\title{
LEIOMYOMA, A MAJOR CAUSE OF ABNORMAL UTERINE BLEEDING
}

Sreeja Rani. V. R, Sindha Thomas

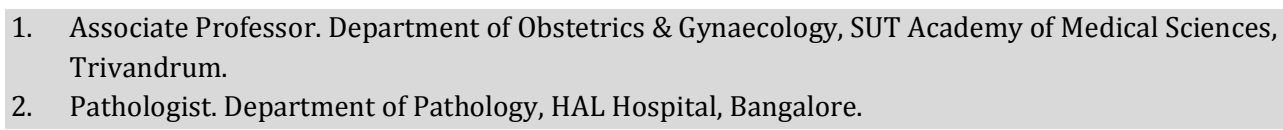

\section{CORRESPONDING AUTHOR:}

Dr. Sreeja Rani. V. R, Flat No.308, Nandi Manomay Arcade,

Sai Lotus Layout, Rajarajeshwari Nagar,

Bangalore- 560098.

E-mail: sreeja546@yahoo.co.in

ABSTRACT: INTRODUCTION: Abnormal uterine bleeding is a common complaint for which many patients in the perimenopausal age group undergo hysterectomy. The objective of this study is to analyze the causes of AUB in subjects who had hysterectomy. MATERIAL AND METHODS: The pathological specimens from 100 patients who had hysterectomy for AUB between January 2012 and January 2013 were studied based on the gross and microscopic appearance. RESULTS: Leiomyoma alone was the most common cause of AUB $(54 \%)$ in patients who had hysterectomy. Leiomyoma was associated with adenomyosis in $20 \%$ cases and adenomyosis alone was seen in 10\%. Endometrial cancer was found in 2\% of patients. CONCLUSION: Leiomyoma is the most common indication for hysterectomy in women with AUB between 40 and 50 years. It may occur alone or may be associated with conditions like adenomyosis or endometrial polyps.

KEY WORDS: Adenomyosis, abnormal uterine bleeding, hysterectomy, leiomyoma

INRODUCTION:-Abnormal uterine bleeding is one of the common complaints of patients in the reproductive age group consulting a gynaecologist. It can occur at any time from puberty to menopause. There are various causes of abnormal uterine bleeding and management differs according to the cause. Hysterectomy still remains as a definitive treatment of abnormal uterine bleeding for a large group of patients. Leiomyoma of the uterus is one of the major causes of abnormal uterine bleeding in Kerala, South India. Though many leiomyomas are asymptomatic, symptomatic leiomyomas necessitate hysterectomy in perimenopausal women. It is diagnosed preoperatively by ultrasound examination and the diagnosis is confirmed by gross and microscopic examination of the surgically removed uterus. Adenomyosis is another common cause of abnormal uterine bleeding which may occur alone or in association with leiomyoma.

The objective of this study is to investigate the etiology in patients of different age groups who underwent hysterectomy for abnormal uterine bleeding.

MATERIAL AND METHODS:-This is a retrospective study carried out on pathological specimen of consecutive patients who underwent abdominal hysterectomy for abnormal uterine bleeding in a teaching hospital at Kerala, South India. The study was done from January 2012 to January 2013. The specimens were examined by two qualified pathologists and diagnosis was based on the gross and microscopic appearance of the specimen. The causes of abnormal uterine bleeding and the prevalence of each condition in different age groups are analyzed. 
RESULTS: A total of 100 eligible cases were analyzed. Mean age of the patients was 45 years; the range between 33 and 57 years. The most common histopathological diagnosis was leiomyoma (53\%) followed by adenomyosis occurring with leiomyoma (20\%). The other causes include endometrial polyps and malignancy of the endometrium (Table 1). No specific cause for abnormal uterine bleeding was identified in four patients.

Leiomyoma(figure 1) and adenomyosis(figure 2) were the most common causes of abnormal uterine bleeding in patients who underwent hysterectomy between 41 and 50 years(Table 2). Endometrial polyps were mostly seen among women over 40 years. Endometrial adenocarcinoma was the cause of abnormal uterine bleeding in two patients who were above 50 years.

Table 1 Causes of AUB in patients who underwent hysterectomy.

\begin{tabular}{|l|l|}
\hline Diagnosis & $\begin{array}{l}\text { Percentage of } \\
\text { cases }\end{array}$ \\
\hline Leiomyoma & $54 \%$ \\
\hline Adenomyosis & $10 \%$ \\
\hline Adenomyosis with leiomyoma & $20 \%$ \\
\hline Polyp & $5 \%$ \\
\hline Polyp with leiomyoma & $4 \%$ \\
\hline Polyp with adenomyosis & $1 \%$ \\
\hline Malignancy & $2 \%$ \\
\hline No specific cause identified & $4 \%$ \\
\hline
\end{tabular}

Table 2 Distribution of cases of AUB according to age group.

\begin{tabular}{|l|l|l|l|l|l|l|l|l|}
\hline Age groups & $\begin{array}{l}\text { AUB- } \\
\mathrm{L}_{1}\end{array}$ & $\begin{array}{l}\text { AUB- } \\
\mathrm{A}_{1}\end{array}$ & $\begin{array}{l}\text { AUB- } \\
\mathrm{A}_{1} \mathrm{~L}_{1}\end{array}$ & $\begin{array}{l}\text { AUB- } \\
\mathrm{P}_{1}\end{array}$ & $\begin{array}{l}\text { AUB- } \\
\mathrm{P}_{1} \mathrm{~L}_{1}\end{array}$ & $\begin{array}{l}\text { AUB- } \\
\mathrm{P}_{1} \mathrm{M}_{1}\end{array}$ & $\begin{array}{l}\text { AUB- } \\
\mathrm{M}_{1}\end{array}$ & $\begin{array}{l}\text { No specific } \\
\text { cause }\end{array}$ \\
\hline $\begin{array}{l}30-35 \\
\text { years }\end{array}$ & 2 & & & & & & & \\
\hline 36-40years & 7 & 3 & 3 & & & 1 & & \\
\hline 41-45years & 23 & 4 & 9 & & 1 & & & 2 \\
\hline 46-50years & 21 & 3 & 7 & 1 & 1 & & & 1 \\
\hline 51-55years & 1 & & 1 & 4 & 2 & & 1 & 1 \\
\hline 55-60years & & & & & & & 1 & \\
\hline
\end{tabular}

DISCUSSION:-Abnormal uterine bleeding (AUB) is defined as bleeding from the uterine corpus that is abnormal in volume, regularity and/or timing.[1] It could be acute or chronic.[2] When the abnormal uterine bleeding is present for at least 6 months, it is classified as chronic abnormal uterine bleeding. Acute abnormal uterine bleeding is an episode of heavy bleeding which requires immediate intervention to prevent further blood loss. Acute abnormal uterine bleeding may also occur in patients with chronic abnormal uterine bleeding. Abnormal uterine bleeding can occur any time in reproductive age group ranging from heavy menstrual bleeding in adolescents to post menopausal bleeding.

The International Federation of Gynecology and Obstetrics (FIGO) has approved a new system for classification of AUB in non gravid women of reproductive age. There are nine main categories and they are arranged according to the acronym PALM-COEIN which points to the cause of AUB. 


\begin{tabular}{|l|}
\hline Polyp \\
\hline Adenomyosis \\
\hline Leiomyoma \\
\hline Malignancy \& hyperplasia \\
\hline
\end{tabular}

\begin{tabular}{|l|}
\hline Coagulopathy \\
\hline Ovulatory dysfunction \\
\hline Endometrial \\
\hline Iatrogenic \\
\hline Non classified \\
\hline
\end{tabular}

According to the new system, the terms "menorrhagia", "metrorrhagia", "hypermenorrhoea" and "dysfunctional uterine bleeding" have been abandoned.[1] The term 'heavy menstrual bleeding' is to be used in place of 'menorrhagia'. The size of the uterus is not included in the present classification. Also in case of leiomyomas, the number and location of leiomyomas are not included.

When a woman in reproductive age group presents with abnormal uterine bleeding(AUB), history, examination and investigations are needed to rule out pregnancy. Haemoglobin estimation and a full blood count including platelets are to be done. Structural anomalies of the uterus can be made out by a transvaginal ultrasound examination.[3] When there is regularity in time and flow of the menses, anovulation is usually ruled out.[4] Measurement of serum progesterone in mid luteal phase or a timed endometrial biopsy may be used to confirm ovulation.[1] To rule out coagulopathies, a structured history, Von Willebrand factor assay and ristocetin cofactor assay may be done if necessary.[5] For endometrial assessment, many methods can be used like transvaginal scan, hysteroscopy, saline infusion sonohysterography or endometrial biopsy.[6]

In the present study, the commonest cause which necessitated hysterectomy was leiomyoma. Hysterectomy is the most effective treatment for leiomyoma in case of symptomatic fibroids and it offers high rate of patient satisfaction.[7] Other management options include myomectomy and uterine artery embolisation. Magnetic Resonance Guided Focused Ultrasound (MRgFUS) also has a role in treatment of fibroids in selected women.[8] Adenomyosis and endometrial polyps were the other common causes of AUB. Adenomyosis often co exists with leiomyoma. Adenomyosis in perimenopausal women is often treated with hysterectomy while in younger women, adenomyomectomy and Magnetic Resonance guided focused ultrasound are other management options.[9,10]

In our study, $73 \%$ of patients underwent hysterectomy for abnormal uterine bleeding between 41 and 50 years. Of these, 39\% were 45 years or less. Leiomyoma alone was the causative factor for hysterectomy in $44 \%$ of patients between 41 and 50 years. The overall prevalence of leiomyoma in the study was found to be $78 \%$ and that of adenomyosis was $31 \%$. Similar incidence of fibroids(70.6\%) was seen in a French study analyzing the indications for abdominal hysterectomy.[11] A similar study from Iran showed adenomyosis as the leading histopathologic diagnosis in patients who underwent hysterectomy for abnormal uterine bleeding.[12] A study done in Karachi analyzed cases of hysterectomy done for non neoplastic conditions. [13] It showed adenomyosis to be the commonest pathology followed by leiomyoma. However, in another study done in USA analyzing hysterectomy for benign conditions on 32,321 patients, leiomyoma was found to be the leading indication.[14] The overall prevalence of endometrial polyps was only $10 \%$ in our study. A study from Brazil showed endometrial polyp as the most frequent hysteroscopic finding (33.9\%) in patients with abnormal uterine bleeding but histological diagnosis in the same study showed endometrial polyp in only $27.5 \%$ patients .[15] 
CONCLUSION: According to our results, leiomyoma is the most common indication for hysterectomy in women with abnormal uterine bleeding between 40 and 50 years. It may occur alone or may be associated with conditions like adenomyosis and endometrial polyps. Although many options of treatments are available, hysterectomy is still preferred for leiomyoma in perimenopausal women.

\section{REFERENCES}

1. Munro MG, Critchley HO, Broder MS, Fraser IS; FIGO Working Group on Menstrual Disorders. FIGO Classification system (PALM-COEIN) for causes of abnormal uterine bleeding in non gravid women of reproductive age. Int J Gynaecol Obstet.2011;113(1):313.

2. Chuong CJ, Brenner PF. Management of abnormal uterine bleeding. Am J Obstet Gynecol.1996;175(3):787-92.

3. Telner DE, Jackubovicz D. Approach to diagnosis and management of abnormal uterine bleeding. Can Fam Physician.2007;53(1):58-64.

4. Malcom CE, Cumming DC. Does anovulation occur in eumenorrheic women? Obstet Gynecol 2003;102:317-8.

5. Kouides PA, Conard J, Peyvandi F, Lukes A, Kadir R. Hemostasis and menstruation: appropriate investigation for underlying disorders of hemostasis in women with excessive menstrual bleeding. Fertil Steril 2005;84(5):1345-51.

6. Clark TJ. Outpatient hysteroscopy and ultrasonography in the management of endometrial disease. Curr Opin Obstet Gynecol.2004;16(4):305-11.

7. Marret H, Fritel X, Ouldamer L, Bendifallah S, Brun JL, De Jesus I et al. Therapeutic management of uterine fibroid tumours: updated French guidelines. Eur J Obstet Gynecol Reprod Biol.2012;165(2):156-64.

8. Dobrotwir A, Pun E. Clinical 24 month experience of the first MRgFUS unit for treatment of uterine fibroids in Australia. J Med Imaging Radiat Oncol.2012;56(4):409-16.

9. Pepas L, Deguara C, Davis C. Update on the surgical management of adenomyosis. Curr Opin Obstet Gynecol.2012;24(4):259-64.

10. Polina L, Nyapathy V, Mishra A, Yellamanthili H, Vallabhaneni MP. Noninvasive treatment of focal adenomyosis with MR-guided focused ultrasound in two patients. Indian J Radiol Imaging.2012;22(2):93-7.

11. 11.de Meeus JB, Body G, Lemseffer J, Nitrungwa J, Descamps P, Fignon A, Lansac J. Are there still indications for an abdominal hysterectomy? 340 cases. J Gynecol Obstet Biol Reprod.1992;21(5):513-8.

12. Mobarekh MD, Maqhsudi A, Rashidi I. Adenomyosis among samples from hysterectomy due to abnormal uterine bleeding in Ahwaz, southern Iran. Adv Biomed Res.2012;1:49.

13. Ahsan S, Naeem S, Ahsan A. A case notes analysis of hysterectomy performed for nonneoplastic indications at Liaquat National Hospital, Karachi. J Pak Med Assoc 2001;51(10):346-9.

14. Jacobson GF, Shaber RE, Armstrong MA, Hung YY. Hysterectomy rates for benign indications. Obstet Gynecol 2006;107(6):1278-83.

15. Lasmar RB, Dias R, Barrozo PR, Oliveira MA, Coutinho Eda S, da Rosa DB. Prevalence of hysteroscopic findings and histologic diagnoses in patients with abnormal uterine bleeding. Fertil Steril 2008;89(6):1803-7. 
Interlacing bundles of smooth muscle cells in leiomyoma. H\&E X100.

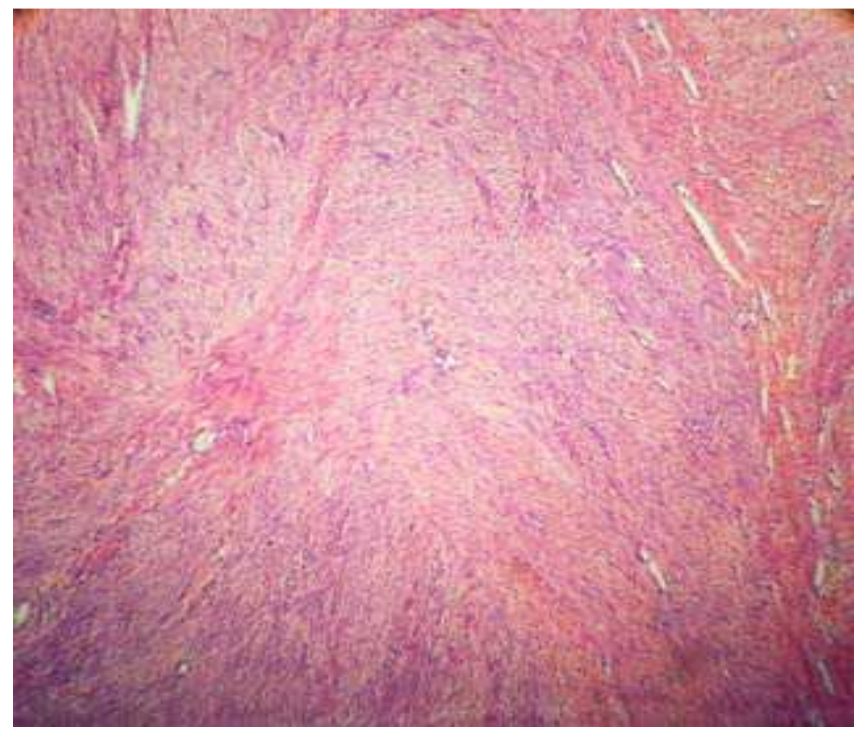

Endometrial glands with stroma embedded deep within myometrium.H\&E X100.

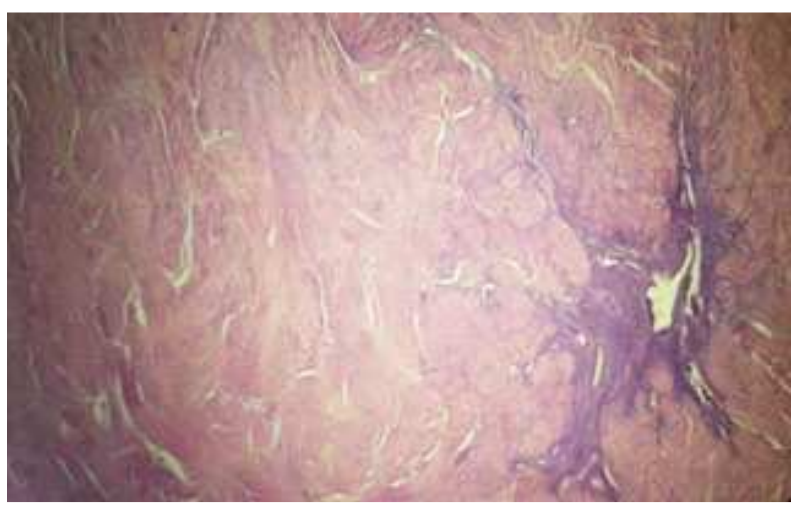

